\title{
Problem Based Learning Model: A Collection from the Literature
}

\author{
Alias Masek (Corresponding author) \\ Faculty of Technical Education, Universiti Tun Hussein Onn Malaysia \\ 86400 Batu Pahat, Johor, Malaysia \\ Tel: 60-1-7747-2042Ｅ-mail: aliasmasek@gmail.com \\ Professor Dr. Sulaiman Yamin \\ Faculty of Technical Education, Universiti Tun Hussein Onn Malaysia \\ 86400 Batu Pahat, Johor, Malaysia \\ Tel: 60-7-453-8206 E-mail: sulaimn@uthm.edu.my
}

The research is financed by Universiti Tun Hussein Onn Malaysia, under short-term research grant.

\begin{abstract}
In Malaysia, there is a growing recognition for innovative teaching and learning methods, such as Problem Based Learning (PBL), in engineering education in order to develop competence graduates. This paper addresses the need on the PBL approaches that fits into Malaysian engineering education scene, in particular with respect to technical engineering education in polytechnics. This paper first reviews several international PBL models, and also several successful pilot projects that conducted in Malaysia. Then, the lessons learned are used as a reference to formulate a PBL model that may fit into the Malaysian polytechnic's education system. An exemplary model of PBL has been developed, which constitutes the key factors that determine the success of PBL implementation. This model is pending for experimentation to examine its effectiveness, in shaping strong technical skills, personal skills, and higher order thinking skills, amongst Malaysian technical graduates.
\end{abstract}

Keywords: Problem Based Learning, Engineering education, Technical education, Curriculum design, Active learning

\section{Introduction}

Breakthroughs in the classic PBL models, it generally can be categorised into two types, namely; pure and hybrid PBL model (Savin-Baden, 2007). The pure PBL model refers to the model that is implemented in fully problem based methodology, and based on the McMaster medical school PBL model. The implementation is generally without any lectures or tutorial sessions, and students are typically working in a small group. The hybrid PBL model is in turn, embedded with lectures and tutorial sessions to support students' learning.

To date, many of these classic PBL models are adapted into a variety of new programmes and across all disciplines. As a result, the pure PBL models become difficult to be distinguished, and there is a tendency for universities to adapt the hybrid PBL model in their curriculum. This is due to the nature of PBL approaches, which are easy to be adapted into different structures of institutional curriculum, and also according to the specific purpose. The purpose of PBL implementation has always been the primary concern, and therefore the PBL model should be adapted according to five purposes as follows (Savin-Baden, 2000):

i) PBL for epistemological competence. Knowledge is more or less proportional but students are expected to be competent in knowledge application and management in solving the problem.

ii) PBL for professional action. Knowledge is valued by practical application and performance, and the problem scenario is based on real-world application.

iii) PBL for interdisciplinary understanding. Knowledge is across "know-how" and "know-what", and the problem scenario is to bridge the gaps between these two areas.

iv) PBL for trans-disciplinary learning. Knowledge is to understand the boundaries across disciplinary, and the problem scenario is presented in open-ended to promote critical stance. 
v) PBL for critical contestability. Knowledge is in contingent, contextual, and constructed within multidimensional problem scenarios, and offers multidimensional solutions with an opportunity to interrogate in order to build the disciplinary understanding with credential.

Although the PBL models can be adapted according to a specific purpose, this process must be based on extensive research works to define a specific formula for adapting PBL into an existing curriculum. According to Savin-Baden (2007), the utilization of PBL can be seen either as an instructional strategy or as a curriculum design. PBL can be used as a component of the programme, module, or mixed with other approaches if PBL is seen as an instructional pedagogical method. On the other hand, PBL may become a philosophy in the design of curriculum to integrate both curriculum design and learning.

This paper first describes the PBL context of implementation, which is in this case is the Malaysian polytechnics. Then, this paper provides the summary of review from several established PBL models, which constitutes the key factors that contribute to the success of PBL implementation. Several local PBL pilot studies that conducted in Malaysia are also included. Next, an exemplary model of PBL is outlined, which is formulated based on several principles in designing specific PBL instructions.

\section{Polytechnics in Malaysia}

A large portion of technical education courses are offered in polytechnic institute. It is therefore, the polytechnic institutions have become a chosen route in producing semi-professional technical workers, for students who are keen to acquire technical knowledge, yet unable to enrol in the first-tier university engineering courses (Esa et al., 2009). Based on a statistical report, a total of 27 polytechnics are currently accommodating more than 86,000 students from various courses including engineering, commerce, and services (DPCCE, 2009). From this figure, 28 engineering programmes are offered at diploma level, which includes electrical engineering, electronic, civil, mechanical, and mechatronic engineering (DPCCE, 2009).

Throughout these programmes, students will generally undertake six semesters to complete at least 93 credit hours, in a minimum period of three years (DPCCE, 2009). Students who enrol in the first year will be taught with the basic concepts and theoretical knowledge in engineering. The traditional method of lecturing is employed for several fundamental subjects, such as Engineering Mathematics, Electrical Technology, Electronic Systems, Microcontroller, and Computer Application. In addition, there are another two special Engineering Laboratory courses, which account for six credit hours for students to hone their hands-on skills. The assessment method for these subjects comprise of at least $60 \%$ of coursework, which includes mini projects, assignments, quizzes, and tests, and another $40 \%$ is devoted for final examination to be counted as students' overall grade (DPCCE, 2009).

In the recent campaign to improve the quality of teaching and learning, the pedagogical in polytechnic is advocated to focus more on Student Centred Learning (SCL) approach, such as the PBL method (DPCCE, 2008). Within this, the polytechnic graduates are expected to grow and develop with other personal skills and abilities, such as problem solving, creative and critical thinking, social skills, and personal value, alongside with strong technical skills. However, an observation on the current implementation reveals that there is much room for improvement for SCL implementation. The educational system in polytechnic has been preoccupied with the traditional form of education and assessment, which is seen as contradicting the spirit of SCL approach. The SCL implementation, which is using PBL approach, appears ineffective without specific guidance through a specific and customized PBL model. It is hoped that this effort will produce a significant contribution to the recent campaign, as well as helping polytechnic graduates to meet the expectations.

\section{Related Works}

Several selected PBL models have been reviewed, in order to identify the key factors that contribute to the success of PBL implementation. Without delving into the specific disciplines or the particular models, the discussion focuses on three critical components, which includes the format and design of the problems (Wee, Kek and Sim, 2001; Hung, 2006), the role of the tutors (Wee, Kek and Sim, 2001; Wee, 2004), and the assessment strategies (Gijbels et al., 2005). In order to gain a better understanding, the discussion will also specifically include the programme structures.

\subsection{Lessons from PBL Models}

Throughout the PBL models in the higher education context, generally each offers unique approaches according to a specific purpose, subject, discipline, institutional culture, national policy, and national educational framework. These models also differ in approach, design and problem format, implementation method, and assessment strategy. The summary of the review is presented as follows: 


\subsubsection{The Programme Structures}

Generally, PBL can be implemented at several levels according to the subject level, course, and institutional level. Typically at each level, PBL inclusion is gradually dominating students' time from $25 \%$ to $90 \%$ throughout the programme. This would allow students who are in the first year, to discover the PBL method and develop their necessary skills in order to sustain throughout the programme. Such programme structure can be observed, for example in University of Southern Queensland's PBL model (Young, 2005), Temasik Polytechnic PBL model (Temasik Polytechnic, 2009), and Aalborg University PBL model (Kjersdam and Enemark, 1994).

In the first two years in undergraduate level, the focus is generally developing students' basic skills in learning independently (Lennox, 2003; Lahtinen, 2005). The key skill to be developed is "learning how to learn", and this can be achieved by first developing their collaboration skills, communication skills, teamwork, self-directed learning, self-assessed, and research skills (Moesby, 2005). In the remaining years, students typically spend more times to develop a strong theoretical knowledge, problem solving skills, and professionalism with regard to their educational disciplines.

In addition, in the first two years, the syllabus is typically delivered through thematic modules (Kolmos et al., 2007; Oliveira and de Oliveira, 2009). On the other hand, some PBL models also retain the traditional method of lecturing for the fundamental subjects (Wee, 2004). Supporting courses are also offered to fill up the gaps within the thematic modules (Oliveira and de Oliveira, 2009), and are designed to be different than the traditional method. In some cases, voluntary courses are offered as additional knowledge, where the content may or may not be related to the students' project at hand (Cheesman and Heilesen, 1999).

In some models, the curriculum for projects or thematic problems is organized as a repeated module (Lahtinen, 2005), or as a repeated process (O'Grady and Alwis, 2002). However, this module is designed to gradually increase in complexity, and targeting different level of competencies for each stage. For instance, in Republic Polytechnic's PBL model, students repeat the similar process of daily problem solving to solve different problems. In this case, students are expected to be competent in problem solving, as well as hands-on in technical skills. In Lahti Polytechnic PBL model, the specific topics in engineering are embedded into a thematic module, and it is repeated for each year of the study in order to develop a strong theoretical knowledge and technical skills (Lahtinen, 2005).

\subsubsection{The Format of the Problems}

The PBL 'problem' is a starting point for all stages in the PBL process. Although the problem formats, problem sources, and the methods of delivery are different between models, generally these models are using real-world problems that were reconstructed to meet the syllabus needs. The problem is simulated into other forms that are possible to be used as learning tools. It is typically designed based on several sources including the government agencies, proposal from industries, students' proposal, and lecturers' interest (Kolmos et al., 2007). In some other cases, students attend an industrial attachment, where they would solve a real-world problem in an actual workplace environment (Lahtinen, 2005).

An ideal problem to stimulate learning is described by the characteristics, such as authentic, complex, open-ended, thematic, and it must always fall within students' capability to solve (Wee, 2004). The problem is commonly designed ranging from easy to difficult throughout several stages (Barrows and Tamblyn, 1980; Woods, 2000; Lahtinen, 2005). Furthermore, the method of problem delivery must be suitable and understandable by the students, and typically in the form of written scenarios, case-based, events, product prototypes, and also in the form of laboratory sheets (Lennox, 2003; Wee, 2004).

In certain cases, the problem is not determined by the facilitator, instead students decide for themselves (Cheesman and Heilesen, 1999; Kolmos et al., 2007). For instance, in Roskilde University's PBL model, students are given the freedom to develop their problem solving proposal, but it must fulfil several requirements, in order to meet the pre-determined standards. This method however, provides some autonomy to students in making decision, and it appears to be practical for students in determining their learning experience according to their interest.

\subsubsection{The method of Implementation}

PBL is implemented differently with respect to several variables such as group size, procedures, tutoring concept, and the facilitator's role. In PBL environment, the disciplines, year of the course, physical spaces, time frames, and the size of the project will determine the number of students in a PBL group. For example, in Aalborg University's PBL model, the group size ranges from two to eight members across all disciplines (Kolmos et al., 2007). However, in some cases, 10 members are appropriate for particular projects, while four members are too 
small in some other cases (Kolmos et al., 2007). Engineering course typically requires five to six members during the early year of the courses, and becomes smaller to two to three members upon approaching the final year. There must be a balance between the size of the project and the time frame in order to determine the appropriate number of members in a PBL group.

In the other context of PBL implementation methods, generally, students are working systematically throughout several stages. The stages are similar to that of the "seven-jump" tutorial process in Maastricht PBL Model (Schmidt, 1993). These processes include a mixture of learning strategies, such as brainstorming, analysing, researching, reasoning, exploring, and explaining. Each process will be functioning well when a person who acts as a facilitator is assigned to guide students' learning.

From the method of facilitation perspectives, the concept of tutoring depends on the purpose, and may be implemented differently according to the facilitator's skills. The facilitator is responsible to guide students throughout the learning process by posting some questions, provoking, and to a certain extent, providing links to information sources. The facilitator is also responsible to guide students through the process of sharing information, discussion, brainstorming, as well as to help them to arrive at a group consensus, and making decision (e.g. Schmidt, 1993; O'Grady and Alwis, 2002). However, this is not always the case since the group is faced with many issues and is dealing with dynamic and diversity of group members. Facilitator must create an environment for the learning process to occur smoothly, by assisting the students when confronted with group conflicts (Sabburg, Fahey and Brodie, 2006; Brodie and Gibbings, 2007).

Amongst the facilitation concepts in several PBL models, a tutorless concept in McMaster PBL model appears as an exemplary model of facilitation (Woods, 2000). The facilitator's interference in students' learning process is minimized to monitor students' progress. The tutorless concept also advocates students to spend more time on self-study and to promote self-directed learning, before they come for a group discussion. However, the implementation of tutorless concept must first empower students with the ability to self-assessed and self-directed learning.

\subsubsection{The Monitoring and Assessment}

Assessment in PBL focuses on different aspects of evaluation, which is based on the main purposes of PBL inclusion. The assessment is typically conducted according to the purpose, either to measure processes or products. The assessment is also determined either based on the project or the block of programme structure. Moreover, the assessment can also be conducted as a group-based assessment or as an individual-based assessment (e.g. Lennox, 2003; Kolmos and Holgaard, 2007; Kolmos et al., 2007). Students are typically awarded with an individual grade even though the assessment is conducted on group basis (Kolmos et al., 2007). This can be done through the implementation of peer assessment strategy, in which the group marks is adjusted based on the peer assessment marks (Lennox, 2003).

However in general, most of the assessment in PBL focuses on assessing process skills (Woods, 2000; O'Grady and Alwis, 2002; Wee, 2004; Lahtinen, 2005). Therefore, the formative assessment is more appropriate, since the PBL advocates more on the learning process. The assessment in PBL is typically implemented as an ongoing process, and concerns on students' skills development. Furthermore, an ongoing assessment is prominently important in ensuring students' learning is always in the right path. In some other practices, the PBL assessment excludes the written final examination, particularly for the model that concerns much on the knowledge applications and technical skills competencies (O’Grady and Alwis, 2002).

The assessment for process skills such as problem solving and knowledge applications, typically takes place at the end of each project completion (e.g. O'Grady and Alwis, 2002; Lennox, 2003). All too often, the process skills assessment is frequently conducted and distributed in parallel with the project or the block of the programme structure. Multiple dimensions and methods are involved, such as short presentation sessions, quizzes, MCQ tests, short-test of concepts, practical demonstrations, and poster presentations (e.g. Foldevi, Sommansson and Trell, 1994; Lennox, 2003). The targeted skills include communication skills, teamwork, research skills, interpersonal skills, and professional skills. In some other cases, the assessment commonly involves external examiners, particularly for those models that jointly collaborate with industry (Kolmos et al., 2007). On the other hand, the assessment to assess products, such as knowledge content and understanding, is typically scheduled at the end of the block or term through a written final examination and open-book test concept (Segers and Dochy, 2001; Wee et al., 2003).

The philosophy of PBL assessment stated that the assessment is a part of learning process (Foldevi, Sommansson and Trell, 1994). Therefore, a feedback comes together with the formative assessment to support students' learning. The feedback must also be an ongoing process, and it is equally important as the formative assessment. 
The tandem process of formative assessment and feedback would determine the success of PBL implementation (Gijbels et al., 2005).

In the approach of tutorless concept as described previously, the feedback comes to support students' learning, but not as rigorous as in the regular tutoring concepts. Students are always told to keep up with self-assessment during the learning process (Woods, 2000), in order to ensure that they are always in the right path towards meeting the learning outcomes. However, self-assessment can only be successful when students have a clear definition of their learning objectives. As an example, in Linkoping University's PBL assessment model, the uses of rubric rating scale that defines all the criteria to be achieved was probably the best tool to help students keep up with their self-assessment (Foldevi, Sommansson and Trell, 1994).

\subsection{Lessons from Local PBL Pilot Projects}

In order to fix to the local cultural and educational settings, several local PBL pilot projects have been reviewed. In University Malaya, Said et al. (2005) has proposed a gradual integration of PBL into engineering courses. The integration was suggested to cover $20 \%$ of the course and increased up to $90 \%$ from students in the first year to the final year. The traditional method of lecturing approach was proposed to be retained. Within this, the problem structure was suggested to be subject-centric oriented for the first year students and more comprehensive, interdisciplinary, and thematic problems for students in the final year. The facilitator's responsible was to expedite and bring students through the concept of "learning by doing". They should also be capable in probing students with challenging questions, provoking, encouraging, and creating conducive environment for learning. The assessment should also be equal in assessing both process and product.

In the classroom environment, PBL was implemented as one of the "active learning" techniques (Yusof et al., 2005) in Universiti Teknologi Malaysia (UTM). An example is in the Process Control and Dynamic Course, in which the PBL inclusion dominated almost $70 \%$ of the syllabus, while the rest was using mini lectures and cooperative learning methods. The problems were designed based on the textbook, and each problem comprised of three case studies. Within this, students were administratively assigned into a group of four to five members, which was based on their academic achievements. The floating facilitator concept was used to monitor students' progress. In PBL stage, the PBL groups shared their understanding in several short presentations, and the lecturer immediately provides feedback to them. Students were evaluated based on assignments, quizzes, and peer review. They also write learning journal to record their self-reflection on their learning experience. At the end of the term, students were scheduled for final examination.

Another example in UTM, Syed Hassan et al. (2005) conducted a pilot study to investigate the suitability of PBL in Facilities Planning course. The traditional classes were retained and PBL slots were scheduled within tutorial sessions. Students were triggered by three major problems, and each was embedded with a three sub-problems. Subject-centric problem oriented was assigned, which paralleled with the syllabus progress within a specific timeframe. Students worked in a small group of five members, which was formed based on several attributes including race, gender, learning style, and academic results. Throughout the assessment method, students are evaluated based on several tests, projects, short presentations, quizzes, tutorial performance, and a final examination. Students' progress was also monitored through continuous log books writing and reflective journal. Furthermore, a checklist was used to judge the individual contribution to the group works.

In Universiti Tun Hussein Onn Malaysia (UTHM), Ahmad and Jabar (2007) conducted a pilot study in Computer Engineering programme. Throughout the PBL methods, students are presented with open-ended problem in several small laboratory works. The problems were structured in clearly defined objectives, so that students were aware of the lecturer's expectations and objectives of the laboratory tasks. Students cooperatively worked in a group comprised of four to five members. They were assessed through several methods, which included the project progress presentations, poster presentations, small task lab work, and a final presentation. The evaluation was based on several areas such as oral presentations, process skills, report writings, group managements, and attitudes. Interestingly, the authors have developed few special rubric rating scales to facilitate the assessment process.

In 2005, Bakar and Rahman conducted a pilot study in a computer programming course in Kolej Universiti Kejuruteraan and Teknologi Malaysia (KUKTEM). The PBL was incorporated into laboratory work, while the lecturing sessions were retained as usual. The problems were generated based on the existing product prototypes, and students discussed to identify several shortcomings from all possible aspects including designs, integrations, and functions. Within this, students proposed a new problem statement and they were expected to improve the prototype. Students worked in a group of two to three in redesigning circuit, reprogramming, and interfacing software and hardware peripherals within an open-ended timeframe. The project was fully evaluated base on 
formative assessment, which included several written tests, quizzes, assignments, project presentations, and report writings without final examination.

\section{The PBL Design Principles}

The recent globalization is advocating technology integration, labour mobility of expert and professionals, and knowledge diffusion (Hoekman and Javorcik, 2006). Many international companies have been operating in Malaysia for many years, and it is expected to increase in conjunction with the recent government policy. Within this, the speculation of the globalization of the workplace culture, particularly in engineering field is a sound rationale.

Therefore, the work by Jonassen, Strobel and Lee (2006) who conducted a study to investigate the real workplace engineering requirements might also be applicable in the Malaysian context. The study involved 106 engineers who voluntarily participated in the structured interview. This study illustrated several themes with regard to the workplace engineering problems. The authors defined several implications that must be embedded within engineering education, which included:

i) Workplace transfer - education goals must foster workplace transfer.

ii) Problem based learning - students' learning is self-monitored and self-directed.

iii) Complex and ill-structured problem - encourage wide areas of experience.

iv) Different kinds of problem - encourage multiple skills development.

v) Problem based learning environment - support students' learning.

vi) More meaningful collaboration - group diversity provides meaningful interaction.

To learn from the lesson, the curriculum developments that underpin PBL philosophy must integrate three compulsory elements; which include the understanding of contextual knowledge, skills competencies, and attitude (Wee, 2004). These compulsory elements must be integrated within PBL instructions synchronized with the following exit outcomes of PBL curriculum (Wee, 2004):

i) What to learn refers to the problem as the curriculum.

ii) How to learn refers to the PBL process.

iii) How much is learned refers to assessment.

The first exit outcome refers to the need of a well-crafted problem which determines what students should learn. A careful consideration must emphasize these three compulsory elements. The second exit outcome refers to the need of the process to achieve the objectives relating to those compulsory elements during PBL implementation. The third exit outcome refers to the need of a well-designed assessment system, in order to determine the depth of understanding on those compulsory elements.

In relations, Moesby (2005) has proposed a strategy to integrate several compulsory elements into PBL curriculum. Moesby emphasizes the personal skills and abilities, and more specifically in cultivating students with knowledge, skills, and attitude. The attributes such as the ability of "learning how to learn", collaboration skills, perceptions of context, academic behaviour, and conflict solving capabilities, can be possibly integrated into the curriculum based on the formulation of visions. Many tools are available in PBL environment that can be used to integrate these attributes. For example, a portfolio and team reflection can be used to foster the skills of "learning how to learn" and collaboration skills.

In addition, to integrate PBL with the existing curriculum, Wee (2004) has suggested two ways in changing the existing conventional curriculum to PBL. The first method is through an injection-based PBL, whereby the PBL implementation is within the boundary of the subject in the existing curriculum. The problem is typically artificial even if they involve real-world instruments. The second method of implementation is through a theme-based PBL. This method requires a facilitator to craft a problem that involves several related subjects in the same theme.

\section{An Exemplary PBL model: A Collection from the Literature}

Several established PBL models have been reviewed, and its critical components have been identified. Then, the identified components were collected and used to develop a new tentative PBL model. In order to fit to the local educational settings, several recent successful pilot projects that were conducted within the Malaysian educational scene, have also been reviewed. The combination has produced an exemplary instructional PBL model, which specifically can be adapted to the local polytechnic's curriculum, and generally for other higher 
educational institutions in Malaysia. This tentative model is explained in details, and is organized according to components as follows:

\subsection{PBL Structure}

The PBL implementation is suggested to be within a subject level. The subject level is appropriate in exploring the feasibility and effectiveness of PBL approach, as the first attempt to implement PBL in polytechnic. Therefore, the subject-centric problem should be designed as a trigger, and mini lectures should be used to fill the gaps within subject-centric problems. However, the mini lectures are suggested to be integrated within tutorial session, and to take place for a maximum of half an hour, according to the contents and objectives of the particular tutorial session.

\subsection{The Format and Design of the Problem}

The problem is suggested to be presented through several formats, which include written scenarios, events, case-based, product prototypes, video, audio, photographs, physical samples, and laboratory sheets. The problem format is according to the suitability of the topics, requirements, objectives, and learning materials that are available in polytechnic laboratories.

The main problem should comprise of several sub-problems, and also integrate at least three topics within the syllabus. Several major problems should cover all topics given in the syllabus. The sub-problems should be structured in its approach and will mix both easy and difficult problems. The sub-problems should be designed to fit with two weeks of working period of problem solving, so as to allow a proper scheduling for problem assignment and independent learning. An artificial problem is proposed, but it mimics the real-world application. The solutions should be open-ended, without any single right or wrong answer.

\subsection{The Implementation Method}

Students are expected to work in a group of five to six members to solve the problem. The first meeting in the first week is to deliver the problem, and students should start to define the problem and learning outcomes. The second meeting in the following week should be devoted for group discussions and short presentation sessions. The operating method during the problem solving process in tutorial sessions is proposed to use the "seven-jump" model as in the Maastricht PBL model.

In the problem solving process, all groups should receive a similar set of problems. There will be no issue of plagiarism, since the problem is designed to have open-ended solutions. In fact, they are encouraged to share their material amongst group members or with other group members. The methods and the problem solutions are expected to be different, but they learn the same concepts and aim for similar learning outcomes. Therefore, when the groups come to share their problem solutions in the short presentation session, they are expected to engage with different methods of solution, but apply the same concepts and principles.

In the first tutorial meeting session, the facilitator should guide the students through the problem solving process. They should begin with the process to understand the problem, and to identify "what they know", "what they do not know", and "what they need to know". This should be done by probing students with questions that lead to students activating their meta-cognitive thinking, and utilizing their previous knowledge and experiences. In the second tutorial meeting session, the facilitator continues with probing questions and monitors students' progress. During the last session of the problem solving process, feedback should be given to each group immediately after a short presentation session. The facilitator should provide a feedback comment on students' progress, which is based on the rubric rating scales that is provided.

\subsection{The Assessment Strategy}

In the first meeting, students should be provided with several rubric rating scales to deliver the facilitators' expectations on the skills to be developed during the PBL process. They should always be encouraged to refer to the rating scales, and keep up with self-assessment during the problem solving process. The rubric rating scales are also suggested to be used in conducting facilitator and peer assessment evaluation.

Several short presentation sessions should be scheduled to diagnose and support students' learning. These short presentation sessions are suggested to be conducted in a group-based format, with all group members presenting their parts. In this session, other groups should perform peer-assessment evaluation. On the other hand, the facilitator also assesses the group performance and awards them with group marks. The results from peer-assessment should be used to modify the group marks, leading to an individual marks. Moreover, the feedback in this case, is to improve students' learning process.

At the end of each problem solving cycle, students are suggested to answer several fixed reflective questions. 
The reflective questions are then submitted immediately at the end of the tutorial session. Students should be properly documenting their parts for each cycle of problem solving as a portfolio. The portfolios are then submitted at the end of the semester for another evaluation upon need basis. In addition, the other forms of assessment are also suggested to be conducted in order to support students' learning. These include quizzes, short essay, and short test on concepts as necessary. It is noted that the facilitator should also perform an informal assessment, through several activities including probing, questioning, observation, which intends to indirectly monitor students' skills development.

\section{Conclusion}

In the growing demand of the industry, polytechnic graduates are expected to be competent in technical skills, as well as in personal skills and abilities, in order to face the challenges in the real workplace environment. Similarly, the growing innovation of pedagogical method, especially in technical engineering has come to narrow the gaps between the real-world and technical education. Learning methods such as PBL has a great potential in producing such desired graduates, and this paper aims to provide a specific guidance on PBL implementation, which comprise of exemplary practices collected from the PBL literature. It is believed that such exemplary practices can specifically expedite the pace to achieve the intended learning outcome, and should be suitable to be accepted as a tool for Outcome Based Education (OBE) in Malaysian universities in general.

\section{References}

Ahmad, A., \& Jabar, M.H. (2007). POPBL experience: a first attempt in first year electrical engineering students. Proceeding of $2^{\text {nd }}$ regional conference on engineering education. Johor: Universiti Teknologi Malaysia.

Bakar, M.S., \& Ab. Rahman, S.N.S. (2005). A kick starts in implementation of PBL in computer programming. Proceeding of $1^{\text {st }}$ regional conference on engineering education. Johor: Universiti Teknologi Malaysia.

Barrows, H., \& Tamblyn, R. (1980). Problem-Based Learning: an approach to medical education: Vol.1. New York: Springer Publishing.

Brodie, L., \& Gibbings, P. (2007). Developing problem based learning communities in virtual space. Proceeding of connected 2007 international conference on design education. Sydney: University of New South Wales.

Cheesman, R., \& Heilesen, S.B. (1999). Supporting Problem based learning in groups in a net environment. Proceeding of computer supported collaborative learning, Stanford, C.A.: Stanford University. [Online] Available: http://akira.ruc.dk/ robin/pubs/CSCL99.html.

Department of Polytechnic and Community College Education (DPCCE). (2008). Strategic plan 2005-2010: engaging industries, empowering communities (revised edition). Kuala Lumpur: Ministry of Higher Education Malaysia. [Online] Available: http://politeknik.gov.my/webjpp2/files/Strategic_Plan_131008.pdf.

Department of Polytechnic and Community College Education (DPCCE). (2009). Quick facts. Kuala Lumpur: Ministry of Higher Education Malaysia. [Online] Available: http://politeknik.gov.my/webjpp2/files/quick\%20facts\%20-\%20english.pdf.

Esa, A., Razzaq, A.R.A., Masek, A., \& Selamat, A. (2009). The perception of students towards the community colleges' courses that offered in Malaysia. Asian social science. 5 (7), 98-107.

Foldevi, M., Sommansson, G., \& Trell, E. (1994). Problem based medical education in general practice: experience from Linkoping, Sweden. British journal of general practice. 44, 473-476.

Gijbels, D., Dochy, F., Van den Bossche, P., \& Segers, M. (2005). Effects of problem-based learning: A meta-analysis from the angle of assessment. Review of educational research, 75, $27-61$.

Hoekman, B., \& Javorcik, B.S. (2006). Global integration and technology transfer. Washington: The World Bank

Hung, W. (2006). The 3C3R model: A conceptual framework for designing problem in PBL. The interdisciplinary journal of problem based learning, 1 (1), 55-75.

Jonassen, D., Strobel, J., \& Lee C.B. (2006). Everyday problem solving in engineering lesson for engineering educators. Journal of engineering education, 95 (2), 139-151.

Kjersdam, F., \& Enemark, S. (1994). The Aalborg experiment: project innovation in university education. Denmark: The University of Aalborg Press.

Kolmos, A., \& Holgaard, J.E. (2007). Alignment of PBL and assessment. Proceeding of $1^{\text {st }}$ international conference on research in higher education. Honolulu: American educational research association. 
Kolmos, A., Kuru, S., Hansen, H., Eskil, T., Podesta, L., Fink, F., de Graaff, E., Wolf, J.U., \& Soylu, A. (2007). Problem Based Learning: special interest group B5. [Online] Available: Teaching and Research in Engineering in Europe (TREE): http://www3.unifi.it/tree/dl/oc/b5.pdf (March 12, 2009).

Lahtinen, T. (2005). Implementation of problem based learning in engineering education. In E. Poikela, \& S. Poikela, (Eds.), PBL in context - Bridging work and education. Finland: Tempere University Press.

Lennox, B. (2003). Teaching engineering through problem based learning. In Problem Based Learning in Engineering. A guide to learning engineering through project. United Kingdom: University Of Nottingham.

Moesby, E. (2005). Curriculum Development for project oriented and problem based learning (POPBL) with emphasis on personal skills and abilities. Global journal of engineering education, 9, 121-128.

O' Grady, G., \& Alwis, W.A.M. (2002). One day one problem at republic polytechnic. Proceeding of 4th Asia-pacific conference on PBL, Thailand: Prince of Songkla University.

Olivera, J.M., \& de Olivera, J.P.E. (2009). Project based learning in engineering: actual case. Proceeding of SEFI 2009 annual conference. European society for engineering education. [Online] Available: www.sefi.be/wp-content/abstracts2009/Oliveira.pdf.

Remedious, L., Clarke, D., \& Hawthorne, L. (2008). The silent participation in small group collaborative learning contexts. Active learning in higher education, 9 (3), 201-216.

Sabburg, J., Fahey, P., \& Brodie, L. (2006). Physics concepts: engineering PBL at USQ. Proceeding of $17^{\text {th }}$ national congress 2006, Australian Institute of physics. Brisbane: RiverPhys.

Said, S.M., Mahamd Adikan, F.R., Mekhiled, S. \& Rahim, A.N. (2005). Implementation of problem based approach in the Department of Electrical Engineering, University of Malaya. European journal of engineering education, 30 (1), 129-136.

Savin-Baden, M. (2000). Problem-Based Learning in higher education: untold stories. Buckingham: Open University Press.

Savin-Baden, M. (2007). Challenging Models and Perspectives of Problem-Based Learning. In E. de Graaff, \& A. Kolmos, (Eds.), Management of change; implementation of Problem-Based and Project-Based Learning in engineering. 9-29. Rotterdam / Taipei: Sense Publishers.

Schmidt, H.G. (1993). Foundations of problem based learning: some explanatory notes. Medical Education, 27, 422-432.

Segers, M., \& Dochy, F. (2001). New assessment forms in problem-based learning: the value-added of the students' perspective. Studies in higher education, 26 (3), 327-343.

Syed Hassan, S.A.H., Yusof, K.M., Abd Hamid, M.K., \& Hassim, M.H. (2005). Problem based learning in facilities planning: A pilot implementation. Proceeding of $4^{\text {th }}$ Asia pacific forum on engineering and technology education, Thailand: Asia-Pacific forum on engineering and technology education.

Temasik Polytechnic. (2009). Problem Based Learning. [Online] Available: http://www.tp.edu.sg/home/about.htm (December, 24, 2009).

Wee, K.N.L, Alexandria, M., Kek, Y.C., \& Mattehew Sim, H.C. (2001). Crafting effective problems for problem based learning. Proceeding of $3^{\text {rd }}$ Asia pasicif conference on PBL. Australia: Australiasian Problem Based Learning Network.

Wee, K.N.L. (2004). Jump Start Authentic Problem based learning. Singapore: Prentice Hall Pearson Education South Asia Pte. Ltd.

Wee, K.N.L., Alexandria, M., Kek, Y.C., \& Kelley, C.A. (2003). Transforming the marketing curriculum using problem-based learning: a case study. Journal of marketing education, 25, 150.

Woods, D.R. (2000). Helping your student gain the most from PBL. Proceeding of second Asia-pacific conference on $P B L$, Singapore. Retrieved from http://chemeng.mcmaster.ca/pbl/Singapore.pdf

Young, F.R. (2005). Education pedagogy for spatial science praxis. Proceeding of SSC 2005 spatial intelligence, innovation and praxis: the national biennial conference of the spatial science institute. Melbourne: University of Southern Queensland.

Yusof, K.M., Tasir, Z., Harun, J., \& Helmi, S.A. (2005). Promoting Problem-Based Learning (PBL) in engineering courses at the Universiti Teknologi Malaysia. Global journal of engineering education, 9, 175-184. 